\title{
O UNICEF e a gestão das famílias: uma análise a partir das ferramentas legadas por Michel Foucault
}

\section{UNI CEF and the management of families: an analysis of legacy tools from Michel Foucault}

\author{
Flávia Cristina Silveira Lemos* \\ Universidade Federal do Pará - UFPA, Belém, Pará, Brasil \\ Cristiane de Souza Santos** \\ Universidade Federal do Pará - UFPA, Belém, Pará, Brasil
}

Diana da Silva Nobre***

Universidade Federal do Pará - UFPA, Belém, Pará, Brasil

Francidalva Costa Paulo****

Universidade Federal do Pará - UFPA, Belém, Pará, Brasil

\begin{abstract}
RESUMO
Neste artigo tem-se o objetivo de problematizar as intervenções do Fundo das Nações Unidas para a Infância (UNICEF), as quais visam a governar as condutas das famílias brasileiras. Analisa-se como as ações do UNICEF se traduzem em práticas individuais e totalizantes de forma simultânea na gestão dos corpos de crianças e adolescentes por meio da medicalização de suas famílias. Este artigo traz uma perspectiva histórica, por meio de Foucault, que é fruto de pesquisas de iniciação científica e de uma dissertação de mestrado em andamento, operando uma crítica política aos modos como agências multilaterais têm atuado, no Brasil, hoje; além disso, focaliza nas maneiras de governar a vida propostas por estas agências, quais interesses estão em jogo e com quais outros atores sociais, institucionais e políticos elas estão aliadas, de maneira neoliberal e com parâmetros da economia política em prol da segurança mundial, na consolidação do que denominam como paz e promoção de direitos humanos.

Palavras-chave: Famílias, UNICEF, Michel Foucault, História, Documentos.
\end{abstract}

\begin{abstract}
The purpose of this article is to problematize the interventions of the United Nations Children's Fund's (UNICEF) that aim to govern the behavior of Brazilian families. It looks at how the UNICEF's actions translate into individual and totalizing practices simultaneously in the management of children's and adolescents' bodies using the medicalization of their families. This paper provides a historical perspective through Foucault is the research's result of an undergraduate research and a dissertation in progress that operates a political critique about the operation of the multilateral agencies today have been active in Brazil and is focused on ways of govern
\end{abstract}


proposed by these agencies, what interests are at stake and witch other social, institutional and political actors are connected to them, in a neoliberal manner and with political economics' parameters in favor of a global security, to the consolidation of what is named as peace and promoting human rights.

Keywords: Families, UNICEF, Michel Foucault, History, Documents.

\section{I ntrodução}

Pretende-se, neste texto, interrogar as práticas de medicalização das famílias do Fundo das Nações Unidas para a Infância (UNICEF), no Brasil, a partir de 1990. Vale notar que é parte de duas pesquisas de iniciação científica, uma financiada pelo $C N P q$ e outra pelo PIBIC/UFPA, no curso de graduação em Psicologia/UFPA, e de uma dissertação de mestrado em Psicologia, no PPGP/UFPA, sobre as práticas do UNICEF direcionadas às famílias brasileiras. Vale sublinhar que este trabalho se insere em uma rede de estudos históricogenealógicos que vêm sendo realizados, desde 2004, examinando as intervenções de organismos multilaterais no Brasil.

Estes trabalhos geraram várias dissertações em psicologia, que tiveram fomento de agências de pesquisa, uma tese de doutorado em história da orientadora destes estudos, financiada pela FAPESP; relatórios de iniciação científica com bolsas, na graduação do curso de psicologia, na UFPA. Todos estes estudos estão articulados ao grupo de Estudos e Pesquisas: Transversalizando, cadastrado no diretório do CNPQ.

\section{Práticas do UNI CEF no Brasil}

UNICEF foi criado, em 1946, em Assembléia das Nações Unidas com o objetivo de assistir às crianças vítimas da II Guerra Mundial. Em 1950, essa agência generaliza a atenção a todas as crianças e adolescentes. "Nesse mesmo ano foi criado, em João Pessoa, capital da Paraíba, o primeiro escritório do UNICEF no Brasil" (UNICEF, 2002, p. 01).

O UNICEF tem um escritório nacional em Brasília e seis escritórios regionais sediados em Salvador, Recife, Fortaleza, São Luís, Belém e São Paulo. No Rio de Janeiro e em São Paulo há ainda os escritórios de mobilização de recursos. O escritório de Brasília procura desenvolver projetos nacionais a partir dos resultados das experiências locais, identificadas, apoiadas e avaliadas pelos escritórios regionais. Além disso, atua junto ao poder público federal para promover leis e políticas públicas em benefício da infância brasileira. (UNICEF, 2002, p. 04). 
Como agência multilateral, o Fundo das Nações Unidas para a Infância desenvolve projetos em parceria com organizações nãogovernamentais e governamentais; atua oferecendo assessorias, fomentando a organização de congressos e fóruns de discussão sobre temáticas ligadas à defesa e garantia dos direitos de crianças e adolescentes; mobiliza o governo federal e os municipais e estaduais, juntamente com o setor privado e entidades da sociedade civil, para realizar seus objetivos. Ou seja, o UNICEF organiza o que Donzelot (1986) chamou de complexo tutelar, porque articula politicamente inúmeras intervenções materializadas por instâncias locais, regionais, nacionais e internacionais, públicas e privadas, atuando em prol da moralização e da normalização de crianças, adolescentes, jovens e famílias.

\begin{abstract}
Para garantir os direitos das crianças e adolescentes e fortalecer suas competências, o UNICEF, com outros parceiros, prioriza a família: organiza campanhas de sensibilização nos meios de comunicação, produz materiais educativos, apóia projetos de prevenção da violência contra meninas e meninos, dentro do ambiente familiar, estimula programas de capacitação das famílias e a criação de mecanismos que garantam sua participação em todos os processos de decisão relativos a seus direitos e de suas crianças (UNICEF, 2002, p. 03).
\end{abstract}

Grande parte das intervenções do UNICEF e do sistema ONU que, de modo geral estão vinculadas aos discursos de economistas, como: Ignacy Sachs e Amartya Sen, que são assessores diretos destes organismos. No caso dos escritos e prescrições do saber da economia baseado nas contribuições de Sen - que esteve ligado às ações do Banco Mundial - há uma ênfase diretriz que une os trabalhos do UNICEF a este banco no que tange às famílias, pois grande parte das dificuldades do desenvolvimento de crianças e de adolescentes e também das práticas de proteção a esta clientela são relacionadas de maneira causal à pobreza e a não escolaridade dos pais das mesmas, em países considerados em desenvolvimento ou não desenvolvidos por estas agências de cooperação internacional.

Conforme Ammann (2003), essa agência ligada à Organização das Nações Unidas (ONU) visa a promover a paz e a segurança mundiais. Destaca-se que essa coligação de Estados, que resultou no Sistema Nações Unidas, age por meio de uma racionalidade fundamentada na filosofia funcionalista, atualizada recentemente em bases sistêmicas. Para tanto, focaliza a família como alvo, por defini-la como a base da sociedade a ser gerenciada, a fim de evitar que a infância se torne um problema de segurança.

Ao chegar ao Brasil, o UNICEF voltou-se diretamente para a atenção à saúde materno-infantil (ROSEMBERG, 2003); aos poucos, foi 
ampliando seu foco de atendimento para crianças e adolescentes, de um modo mais geral. O símbolo do organismo assinala essa preocupação central com a maternidade em relação às crianças, ainda hoje, pois é composto por uma foto de um adulto segurando um bebê no colo, sob o fundo do globo.

Essa agência aciona uma rede de articulações internacionais, trazendo uma visão em parte sistêmica de política, publicando documentos, dentre os quais a publicação de relatórios com análises estatísticas pormenorizadas, com narrativas analíticas de maneira extremamente simplista, que ensejam práticas prescritivas de como devem ser traçadas e efetivadas as políticas públicas, evidenciando um amplo monitoramento dos países em que está presente, pois detalha uma cobertura de avaliação de inúmeros indicadores e os associa a um plano econômico político.

Para realizar tais tarefas, conta com assessorias de pesquisadores e professores universitários, com experts de ONGs e de fundações, além de manter um quadro de funcionários fixo. Também busca apoio financeiro e parceria com bancos internacionais, tais como o Banco Mundial e, no Brasil, com o Itaú; além de ter forte articulação com veículos midiáticos, como a Rede Globo de televisão e um conjunto de empresas brasileiras, o que aponta para certos posicionamentos político-econômicos do UNICEF.

A partir do momento que o UNICEF convida empresas privadas e ONGs a serem os principais agentes de financiamento das políticas sociais dirigidas às crianças e adolescentes, bem como às suas famílias isto implica em afirmar qual a lógica econômica e política proposta pelo órgão em questão. Para o UNICEF, o Brasil deve ser um Estado limpo e enxuto, que promova um quadro jurídico de regulamentações de políticas públicas não estatais que operam, no máximo, com algum subsídio do Estado, mas que sejam efetivamente realizadas pelo terceiro setor e por voluntários membros das comunidades onde as famílias auxiliadas estão inseridas.

O UNICEF tem alcançado importantes resultados no Brasil e essas conquistas devem-se principalmente ao trabalho dedicado de centenas de parceiros com os quais o UNICEF conta há anos. São organizações não-governamentais, órgãos municipais, estaduais e federais, outras agências das Nações Unidas e organismos internacionais, outros escritórios do UNICEF pelo mundo e os comitês nacionais do UNICEF (presentes em 37 países na Europa, América do Norte e Japão), movimentos locais ou comunitários, empresas e organizações do setor privado, pesquisadores, artistas, comunicadores, crianças e adolescentes. Gente reunida num movimento nacional pela infância que, embora informal, mostra sua força cotidianamente na promoção dos direitos das crianças e adolescentes brasileiros. (UNICEF, 2002, p. 26). 
Pode-se afirmar que as práticas desse órgão são sustentadas por uma série de práticas vizinhas, ancoradas em uma grande variedade de saberes e de entrecruzamentos de ações mundializadas, materializando muitos interesses em jogo, para além da proteção de crianças e adolescentes (LEMOS, 2007). Dessa maneira, podemos afirmar que o UNICEF compõe de fato o que Foucault (2004) denominou a produção de um dispositivo, ao relacionar saberes, arquiteturas, subjetividades, equipamentos sociais e poderes heterogêneos.

O UNICEF basicamente é um grande articulador político e agencia, no Brasil, as ações das pastorais, das ONGs nacionais e internacionais, das fundações, de empresas, de lideranças comunitárias, de membros dos governos municipais, estaduais e federal, de universidades públicas e particulares, de voluntários e de emissoras de rádios e TV. Muitos projetos e programas realizados como políticas de atendimento a crianças e adolescentes, no país, são financiadas ou assessoradas pelo UNICEF, mas não são necessariamente executadas apenas por peritos desta agência multilateral. Isto é o que chamamos de ancoragem em práticas vizinhas, já que o organismo em questão mobiliza muitos atores sociais e estabelecimentos, faz induções e se apropria de fragmentos de intervenções pontuais destes diversos equipamentos sociais, montando uma imensa rede híbrida de atuação mundial.

\section{Tecnologias de poder}

No bojo destes acontecimentos problematizados neste texto, vale trazer para debate e como operadores analíticos alguns conceitos e ferramentas de Michel Foucault. Assim, nos apropriamos dos conceitos de disciplina, biopolítica e governo das condutas em nome da segurança como seguridade social postulados por Foucault (1999; $1988 ; 2008 a ; 2008 b)$.

Os mecanismos disciplinares são práticas minuciosas de controle individualizante, que têm uma positividade e permitem o governo das condutas e a produção de saberes. As tecnologias de poder disciplinares gerem de modo capilar os corpos, em função do tempo e do espaço, examinando-os, vigiando-os e sancionando-os por meio das normas como referências, nas adjacências do Poder Judiciário. Disciplina e verdade são articuladas, atravessando as instituições, 0 Estado e os corpos, todavia sem se localizarem exclusivamente nos mesmos, já que a disciplina é um mecanismo de poder que visa ampliar a produtividade concomitantemente à docilidade política dos corpos (FOUCAULT, 1999).

Foucault (1979; 1999) inova, ao pensar as relações de poder para 
além da soberania jurídica e das concepções economicistas que definem poder como repressão, abuso, determinação de classe social ou como ações de instituições designadas de aparelhos do Estado. Desse modo, o controle disciplinar almeja incitar, fabricar subjetividades, ampliar a produtividade e docilizar os corpos, logo, opera por meio de uma positividade.

Já a biopolítica implica uma regulação da população em nome da vida, da constituição de tecnologias de gestão da saúde, atuando nos fenômenos de massa por meio da estatística inferencial e das ciências sociais aplicadas, em especial, da economia política (FOUCAULT, 1988 ; 2008a; 2008b). Em composição com a disciplina, resulta em uma sociedade de segurança, que busca gerir riscos pela via do cálculo de probabilidade (FOUCAULT, 2008a). Há uma relação, para o autor, entre lei e norma, entre a soberania pautada no sujeito de direitos e no direito público, a disciplina e a biopolítica pela via dos mecanismos de segurança, ou seja, a partir de diagramas que se entrecruzam, compondo um emaranhado de táticas e estratégias de poder-saber-subjetivação, na sociedade contemporânea.

A população, objeto da biopolítica, é diferente do povo, que remete ao contrato social. Porém, a disciplina é centrípeta e os mecanismos de segurança são centrífugos. Enquanto a disciplina inclui e controla regularmente, a segurança é mais elástica e moduladora sutil dos indicadores de massa, deste modo, ela opera por um cálculo de risco da liberdade e o custo econômico-político do mesmo.

\footnotetext{
No século XVIII, foi o surgimento da "população", como problema econômico e político: população-riqueza, população mão-de-obra ou capacidade de trabalho, população em equilíbrio entre seu crescimento próprio e as fontes de que dispõe. Os governos percebem que não têm que lidar simplesmente com sujeitos, nem mesmo com um "povo", porém com uma "população", com seus fenômenos específicos e suas variáveis próprias: natalidade, morbidade, esperança de vida, fecundidade, estado de saúde, incidência das doenças, forma de alimentação e habitat (FOUCAULT, 1988 , p. 31).
}

Os saberes, como os psicológicos, os médicos, a Economia política, a Estatística, a Demografia e a Geografia, foram importantes na gestão diferencial das populações, sendo que estas passaram a ser divididas em segmentos governados por estratégias específicas. Vale ressaltar que a gestão da vida é efetuada pela psiquiatrização da infância, pela medicalização dos corpos das mulheres e pelo confinamento da sexualidade na relação de uma família conjugal com fins reprodutivos (FOUCAULT, 1988).

As práticas de medicalização das famílias e da infância mesclam relações de poder disciplinares e biopolíticas, com o objetivo de 
governar condutas das mesmas, ao postularem como esses corpos devem se comportar, viver, pensar, sentir e agir. Contudo, esse controle opera também como proteção de crianças e de famílias, simultaneamente, daí sua dimensão de produtividade, utilidade e expansão da vida. Além disso, os processos de resistência destes corpos frente a essas tentativas de governo se dão no âmbito das ações sobre ações, no plano do cotidiano mesmo dessas práticas políticas e sociais.

\section{Análises das práticas do UNI CEF}

Neste tópico, problematiza-se como o UNICEF lança mão dos saberes da Demografia e da Estatística como vigilância e como demanda de criação de políticas de promoção da vida e gerência dos corpos, no detalhe e na totalidade; ao mesmo tempo acionando a medicalização das mulheres-mães e das crianças, simultaneamente. Entre os objetivos do UNICEF com esses procedimentos, há a preocupação em majorar a vida e torná-la útil e dócil, como se pode verificar abaixo:

Nas últimas décadas, fortes mudanças ocorreram no padrão
demográfico brasileiro [...]. O comportamento reprodutivo da
família brasileira, durante todo esse período, se caracterizava
por uma concepção de família numerosa, típica de
sociedades agrárias e precariamente urbanizadas e
industrializadas. Os valores das taxas brutas de natalidade
oscilavam entre 45 e 50 nascimentos por mil habitantes e as
taxas de fecundidade total variavam entre 7 e 9 filhos, em
média, por mulher (UNICEF, 1998, p. 13-14).

Um dos mais importantes avanços do país na última década foi a queda no índice de mortalidade infantil (UNICEF, 2001, p. 24).

Em uma perspectiva biopolítica, o UNICEF (1998) enfatiza como houve queda nos índices de mortalidade infantil e a entrada maciça das mulheres, no mercado de trabalho urbano. De acordo com esse organismo multilateral, essas alterações populacionais produziram impactos diferenciados na gerência das políticas públicas e na administração orçamentária de gastos, pois, para o UNICEF, um país que não operacionaliza a gestão de seus indicadores de maneira criteriosa não pode realizar uma política com eficácia e eficiência.

Ou seja, quando se tem contenção de gastos públicos para as políticas sociais pelo fato do Estado ter se configurado como mínimo e não mais de bem-estar social, racionalizar a gestão orçamentária e aplicá-la em políticas compensatórias apenas com cautela é uma medida neoliberal e utilitarista. O governo das condutas passa se realizar por meio de uma lógica de gerência empresarial de uma rede 
Flávia Cristina Silveira Lemos, Cristiane de Souza Santos,

Diana da Silva Nobre, Francidalva Costa Paulo

O UNICEF e a gestão das famílias: uma análise a partir das ferramentas legadas por Michel Foucault

de serviços.

Tão importante quanto ter recursos para atender crianças e adolescentes é saber como aplicá-los e analisar o resultado do investimento. Para isso, o UNICEF monitora o gasto dos fundos públicos e capacita gestores municipais para otimizar sua utilização. [...] O impacto dos projetos apoiados pelo UNICEF também é acompanhado permanentemente. (UNICEF, 2002, p. 25).

A última pesquisa sobre Demografia e Saúde Reprodutiva realizada pela Sociedade Civil de Bem-Estar Familiar BEMFAM, em 1996, constata que, para o conjunto do país, mais de $76 \%$ das mulheres em união fazem uso de algum método de controle de sua reprodução. Dentre esses métodos, a esterilização feminina é amplamente hegemônica, sendo utilizada por mais de $52 \%$ das mulheres brasileiras que vivem em união. Esse significativo avanço no uso de métodos destinados à auto-regulação da fecundidade vem ocorrendo de formas variadas sendo, em parte, resultado de iniciativas espontâneas das próprias mulheres e, em parte, fruto da ação e de políticas de difusão originadas de associações e entidades voltadas para o planejamento e bem-estar familiar. Os meios de comunicação têm funcionado como um poderoso indutor de tais práticas, moldando padrões familiares com número reduzido de filhos (UNICEF, 1998, p. 15).

Para tanto, a agência alerta a respeito da relevância em realizar estudos acerca das taxas de reprodução, de natalidade e mortalidade no país, com vistas ao fato dos governantes demandarem a alocação de recursos em projetos e programas específicos a essas transformações demográficas. Tal controle demográfico e orçamentário, articulado ao campo de uma economia política, demonstra a racionalidade de governo da vida forjada pelas práticas do UNICEF, em nome do desenvolvimento socioeconômico do país, funcionando de forma atrelada ao cultivo da saúde, o que configura um poder biopolítico.

A transição demográfica que o país vem vivenciando afeta diferentemente os distintos grupos etários, para os quais deverão ser buscadas soluções específicas - saúde e educação, no caso de crianças e jovens; emprego, no caso dos jovens e adultos, e atenção médica e psicológica e fortalecimento dos programas previdenciários, no caso dos idosos (UNICEF, 1998, p. 25).

Esse organismo relaciona a proteção dos direitos à gestão da sexualidade das mulheres, tanto a da mãe adulta quanto a da adolescente, em uma política de controle populacional e de planejamento familiar, sempre articulada à economia, pois calcula o 
impacto no PIB do país para cada acontecimento, de modo que cada ato infinitesimal seja governado associadamente a um plano mais geral de gerência da população. Em função desses aspectos, 0 UNICEF direciona centralmente suas intervenções na família, afirmando um modelo desta se organizar, sobretudo, no que tange aos procedimentos de medicalização dos corpos.

A proteção, neste caso, é apenas um instrumento para gerir a segurança mundial de maneira a evitar perigos e a evitar prejuízos econômicos. A pobreza das famílias é vista pela ONU e pelo Banco Mundial como impeditiva do desenvolvimento econômico de um país e como um acontecimento que gerará uma série de problemas sociais que colocarão o país em condições de instabilidade política.

Entre as recomendações que são feitas em termos de uma política de saúde e proteção da infância, por meio de estratégias dirigidas às famílias brasileiras, está: a criação de programas voltados para o desenvolvimento de competências familiares de cuidado com a prole e sua difusão, por meio de projetos educacionais específicos e em locais determinados.

O Brasil evoluiu muito, ao longo dos últimos 20 anos, na garantia dos direitos de sua população mais jovem. Avançamos na redução da mortalidade infantil, no acesso a serviços sociais e na conscientização, reforçada pelo Estatuto da Criança e do Adolescente, de que é dever de toda a sociedade assegurar que cada menino e cada menina tenham acesso a educação de qualidade, saúde, igualdade e proteção (UNICEF, 2005, p. 07).

No entanto, precisamos avançar muito mais. Todos os anos, 58 mil bebês ainda morrem antes de completar o primeiro ano de vida, por causas que poderiam ser facilmente evitadas. Cerca de 800 mil crianças não são registradas ao nascer e, sem a certidão, ficam quase invisíveis. Centenas de meninos e meninas são vítimas da violência (UNICEF, 2005, p. 07).

Para o UNICEF, a família é o espaço natural e privilegiado para reverter essa situação, garantindo os direitos de meninos e meninas. Para que ela cumpra bem o seu papel, precisa ser apoiada e fortalecida. Essa tarefa exige o aprimoramento de comportamentos, habilidades e atitudes, desafio que o UNICEF se propõe a enfrentar, em parceria com os governos e organizações não-governamentais (UNICEF, 2005, p. 07).

As competências familiares fazem parte de um amplo programa do Fundo das Nações Unidas para a Infância (UNICEF) denominado Estratégia Família Brasileira Fortalecida (EFBF). Essa estratégia, desenvolvida com a participação de inúmeros parceiros, considera a família como o principal agente na prestação de cuidados à criança. No 
Flávia Cristina Silveira Lemos, Cristiane de Souza Santos, Diana da Silva Nobre, Francidalva Costa Paulo O UNICEF e a gestão das famílias: uma análise a partir das ferramentas legadas por Michel Foucault

entanto, a EFBF reconhece que diversas habilidades da família na promoção do adequado desenvolvimento da criança precisam ser fortalecidas (UNICEF, 2005, p. 02).

Há um forte apelo desse órgão para a criação de projetos e programas de capacitação das famílias como dispositivo de governo de crianças e adolescentes. As práticas desse organismo visam a padronizar as maneiras de ser pai e mãe, de educar as crianças e de promover cuidados. Foucault (2008b) destaca como o liberalismo norte-americano valorizou a formação conjugal, a decisão de ter filhos e as formas de cuidar e educar, como estratégias de um investimento econômico pela via das práticas educativas realizadas pelos pais e pela herança biológica transmitida pelos mesmos aos filhos.

Foucault (2008b) permite assinalar que, atualmente, a agenda dos bancos e dos Estados governamentalizados pela racionalidade neoliberal está marcada pela preocupação em cuidar de cada decisão de um casal e de uma família no plano da educação, saúde e aquisição da cultura em termos de investimentos econômicos, em uma lógica de que cada um de nós se torne um empresário de si mesmo e, em tudo que fizermos, pensemos no fomento de uma vida a capitalizar nos mínimos detalhes até mesmo nos aspectos dos relacionamentos de amizade e afetivos.

Os cuidados têm que começar antes mesmo da criança nascer. A mulher grávida precisa fazer pelo menos seis consultas pré-natais e de orientações sobre como garantir o melhor começo de vida de seu bebê. Os pais, outros familiares e toda a comunidade devem participar do desenvolvimento da criança desde a gestação.

É importante que o pai acompanhe a criança também durante e após o parto, no momento da amamentação, em todas as etapas de seus primeiros anos de vida (UNICEF, 2002, p. 07).

No desenvolvimento de uma criança, existem períodos críticos que dizem respeito à sua capacidade de observar, adquirir linguagem e aprender. Apesar de cada um ser capaz de compensar as oportunidades perdidas, os efeitos acumulados de desnutrição, falta de cuidados de saúde, água não potável, saneamento precário, degradação ambiental, falta de estimulação intelectual e abuso físico ou emocional na primeira infância podem ter conseqüências duradouras para indivíduos e sociedades (UNICEF, 2001, p. 15).

Assim, é vital oferecer à criança diversos estímulos e bons cuidados em sua primeira infância. Aprender, principalmente nos primeiros anos de vida, é muito mais do que ler ou escrever ou se sentar obedientemente em uma cadeira. Aprender envolve oportunidades de exploração do ambiente, descobertas e a capacidade de se adaptar. E as crianças, 
Flávia Cristina Silveira Lemos, Cristiane de Souza Santos, Diana da Silva Nobre, Francidalva Costa Paulo O UNICEF e a gestão das famílias: uma análise a partir das ferramentas legadas por Michel Foucault

principalmente as mais novas, aprendem principalmente com os toques, as sensações e os sentidos [...] (UNICEF, 2001, p. 16).

Nos seus primeiros anos de vida, a principal referência da criança é a família com a qual ela vive. É da família que ela vai receber apoio afetivo, alimentação, cuidados de saúde e que ela vai aprender a falar, brincar, cantar, interagir com os outros. A criança precisa do pai e da mãe. Homens e mulheres estimulam-na de maneira diferente. A criança também precisa de serviços públicos que garantam sua saúde, educação, lazer e que protejam seus direitos (UNICEF, 2002, p. 09).

Gerir detalhadamente as atitudes de crianças, de adolescentes e de seus familiares por um conjunto de práticas heterogêneas e recíprocas significa governar os corpos em serviços de educação, de saúde e em projetos sociais variados, funcionando em uma rede de controle social que extrapola as práticas do Fundo das Nações Unidas para a Infância. Nota-se que há uma positividade da extensão desses controles disciplinares e biopolíticos, na medida em que se ampliam ações de seguridade social, intensificam-se habilidades e produtividade, aumenta-se a saúde, educa-se e gera-se trabalho e renda.

Segurança e proteção estão ancoradas uma sobre a outra, assim, proteger acarreta vigiar e prescrever modos de vida específicos a serem tomados como parâmetros de existência. Assim, não há uma dissociação entre relações de controle social e políticas de garantia de direitos à vida, à educação, à saúde, ao lazer, à convivência familiar e comunitária, à habitação e à alimentação.

Para se desenvolver de forma equilibrada e saudável a
criança precisa de educação, saúde, carinho, proteção,
segurança, estímulos físicos e psicológicos, contatos
pessoais, cultura, esporte, lazer ... a lista é longa. Por isso o
UNICEF rompeu com a divisão das necessidades da criança
por áreas de atuação, como saúde, educação, assistência
social e resolveu organizar sua proposta de trabalho segundo
as três principais fases do ciclo de vida. Há, para cada fase,
um programa que visa garantir o desenvolvimento integral
da criança ou do adolescente (UNICEF, 2002, p. 02).

Ora, o UNICEF cobra políticas de atenção, no Brasil, apoia sua implantação e propõe ampliar a garantia de proteção dos direitos de crianças e adolescentes, contribuindo para a elevação de diversos indicadores sociais e econômicos. Todavia, vigia e monitora o país, intervém maciçamente, em articulação com diferentes organismos governamentais e não-governamentais.

O UNICEF trabalha em parceria com os governos municipais, 
estaduais e federal, com outras agências do sistema ONU, com a sociedade civil e com o setor privado para realizar projetos e apoiar políticas públicas que defendam e promovam os direitos de todas as crianças e adolescentes (UNICEF, 2002, p. 01).

Neste sentido, sabe-se que tais ações não objetivam apenas proteger, mas trazem diversos receituários políticos e econômicos de cunho neoliberal, simultaneamente de maneira prescritiva e com a legitimidade de um órgão que garante zelar por crianças e adolescentes mundialmente, de forma neutra e imparcial e apenas de caráter humanitário.

Porém, o Brasil não é uma vítima passiva das intervenções da UNICEF e de todo o sistema de agências da ONU. Joga-se, no plano da diplomacia, como se fosse um tabuleiro de xadrez, movendo interesses multifacetados, ao aceitar a adesão às propostas do UNICEF, que podem ser ratificadas e não serem cumpridas, ou ainda serem parcialmente seguidas.

\section{O “Kit Família Brasileira Fortalecida”}

O "Kit Família Brasileira Fortalecida" é um manual que apresenta diversos discursos que irão compor grandes séries discursivas de saber-poder, com a finalidade de objetivar e subjetivar as famílias brasileiras, através de uma microfísica do poder com o UNICEF. Por objetivação entende-se uma produção de saberes, como, por exemplo, os saberes que constituem esse documento: família, infância, amamentação etc. Por sua vez, subjetivação é concebida como uma "[...] produção de modos de existência ou estilos de vida" (DELEUZE, 1992). Esse kit é composto por um conjunto de álbuns e faz parte do Programa Família Brasileira Fortalecida pela Educação Infantil, que foi lançado como política pública pelo Ministério da Educação, em convênio com o UNICEF, em 2005.

A análise pressupõe que todo documento é produzido, "[...] toda preservação é seletiva e toda memória, fabricada" (LEMOS et al., 2010 , p. 04), de sorte que se procura desnaturalizar e problematizar os discursos presentes no mesmo, interrogando as relações de saberpoder que atravessam os corpos, produzindo subjetividades.

Em vista disso, busca-se interrogar que poderes o UNICEF procura respaldar, em suas práticas discursivas de saber, quando desqualifica outras como não coerentes, não legítimas. Ou seja, procuram-se problematizar que saberes o UNICEF quer qualificar, desqualificando outros, quando propõe um kit informando às famílias brasileiras como cuidar de seus filhos. 
Cada álbum traz fotos da família, frases curtas imperativas de como zelar e educar, de como cuidar em cada mês de vida da criança de zero a seis anos de vida. Todo o período da gestação também é detalhadamente descrito em termos de um ideal a ser seguido à risca, sob pena de se comprometer a saúde do bebê e, com isto, acarretar futuros problemas sociais para o país.

Vejamos agora alguns dispositivos que podem ser destacados e analisados, quando se toma o kit "Família Brasileira Fortalecida" como objeto de análise. No kit, a família é posta enquanto alvo de cuidado da criança, apresentando-se enquanto um meio natural onde a criança se desenvolve, aprende atos e valores considerados cruciais para a vida adulta que leve a nação ao desenvolvimento social e econômico. Para isso, os relatórios do UNICEF apresentam um modo padrão de ser criança, em que as demais formas concorrentes são tomadas como sendo anormais.

A mulher é eleita pelo UNICEF a agente central de cuidado da criança e da família. Assim, os discursos que compõem os relatórios desse organismo internacional buscam proporcionar a mulher enquanto mãe um conjunto de instruções de como cuidar de seus filhos e gerir sua casa tal qual o oferecimento de um manual de civilização e um guia minucioso de condutas.

Em vista disso, o corpo feminino se mostra enquanto corpo dócil, porque é facilmente moldável às práticas de saber-poder dos discursos do UNICEF. De acordo com Foucault (1999, p.118), "[...] é dócil um corpo que pode ser submetido, que pode ser utilizado, que pode ser transformado e aperfeiçoado". Dessa maneira, pode-se afirmar que a mulher é subjetivada pelos discursos do UNICEF, configurando-se assim numa mãe-ideal, mãe-máquina, facilmente dócil.

A amamentação, isto é, dar o peito, é a primeira e mais importante ação no combate à fome, às doenças e à desnutrição, e no fortalecimento do vínculo fundamental entre mãe e filho. [...] Com a participação da família e da comunidade, a amamentação promove o desenvolvimento infantil adequado. [...] Este álbum foi elaborado para facilitar o trabalho daqueles que no dia-a-dia convivem com gestantes, mães, crianças e suas famílias e têm a grande missão de promover, proteger e apoiar a amamentação. (UNICEF, 2007, p. 38)

É possível observar ainda, nesses relatórios, uma forte ligação da figura da mulher à questão da maternidade, bem como diversos sentimentos que supostamente a cercam como: carinho, amor, dedicação. Sobre essa questão, Rago (1985) salienta que o discurso médico baseava a sua posição sobre o papel materno em uma suposta natureza feminina, que continha uma pureza inquestionável, 
bem como um suposto sentimento inato de amor, como se toda mulher devesse amar e desejar a maternidade, que seria algo intrínseco a ela, à sua natureza.

Existem diversos discursos, nos relatórios do UNICEF, que pretendem disciplinar o corpo feminino e o da criança, tendo por intuito normalizar as condutas, investindo sobre elas um conjunto de "regras" que padronizam seus comportamentos e hábitos.

Existem provas de que as mães orientadas da maneira
correta nos serviços de saúde pública e nos hospitais
amamentam melhor e durante mais tempo. Embora seja um
ato natural, o aleitamento materno nem sempre é fácil de ser
praticado hoje em dia. As mães precisam de apoio emocional
e de informações corretas para terem sucesso na
amamentação (UNICEF, 2007, p. 02).

Segundo Foucault (1999), a disciplina permite estabelecer um tipo de controle sobre o corpo que potencializa suas forças, tornando-o dócil e útil à manutenção de uma determinada ordem. Conforme pode ser observado, através dos discursos do UNICEF, não é suficiente que a mãe saiba o que fazer, é necessário que saiba como fazer, tendo conhecimento das etapas do processo de desenvolvimento da criança biológico e psicológico, tendo noção de procedimentos físicos e afetivo-cognitivos a estimular e fomentar até mesmo na brincadeira e na amamentação.

Bebês que mamam no peito apresentam melhor crescimento e desenvolvimento. Trabalhos científicos identificam que essas crianças são mais inteligentes. [...] Ele é o alimento ideal, não sendo necessário oferecer água, chá e nenhum outro alimento até os seis meses de idade (UNICEF, 2007, p. 04).

Logo, não basta realizar uma atividade desejada, exige-se que se realize do modo como se quer, "[...] com as técnicas, segundo a rapidez e a eficácia que se determina" (FOUCAULT, 1999, p 119).

\section{Considerações finais}

Conclui-se que uma análise dos processos de medicalização dos corpos das mulheres não pode ser dissociada de uma problematização das práticas de governamentalidade liberais, em que direito, poder e verdade são atravessados e interligados por uma economia política. Contudo, o que denominamos governo?

Este é um conceito caro aos trabalhos de Michel Foucault, que, ao estudar as relações de poder, examinou como uma lógica de governo de condutas semelhante, mas não igual, ao que era efetuado pelo 
poder pastoral pelos hebreus, na antiguidade cristã é atualizada, na sociedade contemporânea pelas práticas de seguridade dirigidas às famílias. Entretanto, se antes se geriam condutas para a salvação, agora, elas são gerenciadas em nome da saúde.

O UNICEF seria, então, um articulador político internacional que organiza um campo híbrido de interesses em nome da defesa de direitos humanos de crianças e adolescentes, tendo na família um instrumento de medicalização privilegiado, em termos de uma racionalidade econômica e política neoliberal, para governar condutas individualmente e, de maneira totalizadora, gerir a população.

Vale mencionar que são notórios os efeitos de pressões políticas que esta agência multilateral exerce sobre o Brasil. Também sabemos que as mesmas podem resultar na criação de um conjunto de benefícios variados à população do país, em termos de garantia e defesa de direitos humanos. Mas o que interrogamos é a suposta legitimidade inquestionável do UNICEF e como este se autoriza a prescrever práticas a serem cumpridas de maneira homogênea por todas as famílias, bem como as correlações estabelecidas por este organismo da proteção com a economia e a segurança mundial.

\section{Referências}

FOUCAULT, M. Microfísica do poder. Rio de Janeiro: Graal, 1979. Vigiar e punir: a história da violência nas prisões. Petrópolis/RJ: Vozes, 1999.

Janeiro: 1988.

História da Sexualidade I: a vontade de saber. Rio de A ordem do discurso. 11.ed. São Paulo: Loyola, 2004.

Segurança, território e população. São Paulo: Martins Fontes, 2008 a.

2008b.

Nascimento da Biopolítica. São Paulo: Martins Fontes,

LEMOS, F. C. S. Crianças e adolescentes entre a norma e a lei: uma análise foucaultiana. 2007. 219f. Tese (Doutorado em História) - UNESP-Assis, 2007.

ROSEMBERG, F. A LBA, o Projeto Casulo e a Doutrina de Segurança Nacional. In: FREITAS, M. C. de (org.) História social da infância no Brasil. 5a. ed. - São Paulo: Cortez, 2003.

UNICEF. A infância brasileira nos anos 90. Brasília: UNICEF, 1998.

Situação da I nfância Brasileira. Brasília: UNICEF, 2001.

Fazer Valer os Direitos das Crianças e dos

Adolescentes. Brasília: UNICEF, 2002.

Competências familiares na atenção às crianças de até

6 anos: avaliação em oito comunidades. Brasília: UNICEF, 2005. 
Flávia Cristina Silveira Lemos, Cristiane de Souza Santos, Diana da Silva Nobre, Francidalva Costa Paulo O UNICEF e a gestão das famílias: uma análise a partir das ferramentas legadas por Michel Foucault

- Promovendo o aleitamento materno. $2^{a}$. ed. Brasília: UNICEF/Ministério da Saúde, 2007. - Situação Mundial da Infância. Caderno Brasil. Brasília: UNICEF, 2008.

. Família brasileira fortalecida. Brasília: UNICEF, sem data.

\section{Endereço para correspondência \\ Flávia Cristina Silveira Lemos}

Avenida Almirante Barroso, 2010. Bloco a, apto 1004. Bairro Marco. Belém - PA, Brasil.

Endereço eletrônico: flaviacslemos@gmail.com

\section{Cristiane de Souza Santos}

Centro de Referência de Assistência Social (CRAS) Jaderlândia, Rodovia. Transcoqueiro, Passagem Bom Jesus, no. 04- Una, Ananindeua, PA, Brasil.

Endereço eletrônico: cristianesouza_10@yahoo.com.br

\section{Diana da Silva Nobre}

Av. Augusto Corrêa, n. 01, CEP 66000-000, Instituto de filosofia e ciências humanas. Programa de pós-graduação de psicologia. Universidade federal do Pará. Bairro: Guama. Belém - PA, Brasil.

Endereço eletrônico: diananobre@ymail.com

\section{Francidalva Costa Paulo}

Centro de Referência Especializado de Assistência Social (CREAS) Afuá, Rua 10 de Novembro, 130, CEP 68890, Centro -Afuá - PA, Brasil.

Endereço eletrônico: franpsicosta@gmail.com

Recebido em: 28/07/2011

Reformulado em: 28/09/2011

Aceito para publicação em: 04/11/2011

Acompanhamento do processo editorial: Alexandra Cleopatre Tsallis

\section{Notas}

*Psicóloga/UNESP. Mestre em Psicologia Social/UNESP,Doutora em História/UNESP, Professora adjunta II em Psicologia social/UFPA, Coordenadora do Programa de Pós-Graduação em Psicologia/UFPA.

**Assistente Social/UFPA, Especialista em Saúde Mental e Mestranda em Psicologia/UFPA. Membro do grupo de ensino, pesquisa e extensão Transversalizando.

***Psicóloga/UFPA. Membro do grupo de ensino, pesquisa e extensão Transversalizando.

****Psicóloga/UFPA. Membro do grupo de ensino, pesquisa e extensão Transversalizando. 